\title{
Mitral valve annuloplasty: results in an underdeveloped population
}

\author{
MJ ANTUNES, RH KINSLEY
}

From the Department of Cardiothoracic Surgery, University of the Witwatersrand, Johannesburg, South Africa

ABSTRACT The long term results of mitral valve annuloplasty for pure mitral regurgitation are assessed. Thirty-three of the 100 patients (mean age 16 years) had acute rheumatic carditis at the time of operation. Three basic techniques were used: measured asymmetrical annuloplasty (Reed) in 37 patients, posterior plication annuloplasty in 56, Carpentier ring in seven. There were six early deaths, two of which were valve related. The mean follow up period for surviving patients was 4.8 (SD 1.2) years (range 3-9 years). Fourteen patients died late, all but one from valve related causes. Twenty-five had reoperation and all these had mitral valve replacement. The actuarial survival with initial repair was $56 \%$ at five years and $42 \%$ at eight years. Thirteen patients were lost to follow up. Of the remaining 42 patients, only 27 have an excellent or good clinical result. Eleven patients have only a satisfactory result, with a significant degree of residual or recurrent mitral regurgitation or disability or both. Possible causes of valve related failure were investigated; no significant difference was found between age groups or between acute and chronic cases. Poorer results, of statistical significance, were observed in patients in functional class IV and in those whose operation was performed on an emergency basis. No difference could be found between the results of the three techniques of mitral valve annuloplasty used. This retrospective study indicates that conservative procedures which are limited to annular repair produce inferior results. Valvuloplasty has many theoretical advantages which need practical confirmation.

There is no ideal cardiac valve substitute. ${ }^{1-3}$ Although modern mechanical prostheses are durable and have excellent hydraulic function, ${ }^{4-6}$ they have a high incidence of thromboembolic complications, particularly in the absence of well controlled anticoagulation. ${ }^{7-9}$ On the other hand, there is major concern about the durability of tissue valves, especially in children and adolescents, ${ }^{10-12}$ and the haemodynamic characteristics of porcine valves are unsatisfactory, especially in the smaller sizes. ${ }^{13}$

While South Africa is a first world country with regard to the diagnosis and treatment of heart disease, it supports a large third world population. Rheumatic heart disease is prevalent ${ }^{14}$; patients are frequently young and present late for treatment. Emergency operations are common. ${ }^{15}$ The choice of a substitute valve presents a major dilemma between a mechanical valve in a population in which

Address for reprint requests: Dr MJ Antunes, Department of Cardiothoracic Surgery, University of the Witwatersrand Medical School, York Road, Parktown, Johannesburg 2193, South Africa.

Accepted 27 June 1983 anticoagulation is difficult if not impossible and a tissue valve despite the young age of many of the patients.

Most surgeons are reluctant to attempt conservative mitral valve procedures because of high early and late failure rates. ${ }^{1617}$ Indeed, predictability and reproducibility remain the major uncertainties of any reparative procedure.$^{18}$ Because of the problems of mitral valve substitution, however, we have attempted to conserve the mitral valve whenever possible.

This report describes our experience with isolated mitral valve annuloplasty-as distinct from valvuloplasty-in a hospital for black South Africans.

\section{Patients and methods}

From January 1974 to December 1979 mitral valve operations were performed in 1162 patients at Baragwanath Hospital (table 1). The 100 patients (9\%) who had annuloplasty alone are the subject of 
Table 1 Operations for mitral valve disease (1974-9)

\begin{tabular}{lc}
\hline Procedure & No (\%) \\
\hline Replacement & $742(64)$ \\
Repair & $420(36)$ \\
Valvotomy only & 283 \\
Valvotomy and annuloplasty & 37 \\
Annuloplasty only & 100 \\
Total & $1162(100)$ \\
\hline
\end{tabular}

Table 2 Clinical features of 100 patients having mitral valve annuloplasty

\begin{tabular}{ll}
\hline Mean age (SD) (y) & $16 \cdot 0(9 \cdot 6)$ \\
Male:female ratio & $1: 1 \cdot 5$ \\
NYHA functional class & 19 \\
II & 60 \\
III & 21 \\
IV & 15 \\
Atrial fibrillation & 33 \\
Acute rheumatic carditis & 13 \\
Emergency operation & 11 \\
Associated procedures & 23 \\
Tricuspid annuloplasty & \\
Aortic valve replacement & \\
\hline
\end{tabular}

NYHA-New York Heart Association.

Table 3 Intraoperative pressures ( $\mathrm{mm} H \mathrm{Hg}$ )

\begin{tabular}{lll}
\hline Pressure & $\begin{array}{l}\text { Before bypass } \\
\text { (Mean }(S D))\end{array}$ & $\begin{array}{l}\text { After bypass } \\
\text { (Mean }(S D))\end{array}$ \\
\hline LAM & $23.0(10 \cdot 3)$ & $12 \cdot 1(3.4)$ \\
LAV & $47.6(21.0)$ & $18.5(6.6)$ \\
LVED & $15.2(8.6)$ & $7.8(3.1)$ \\
MVEDG & $49.3(13.8)$ & $3.7(2.7)$ \\
PA & $49.3(10.4)$ \\
\hline
\end{tabular}

LAM-left atrial mean; LAV-left atrial V wave; LVED-left ventricular end diastolic; MVEDG-end diastolic gradient across the mitral valve; PA-pulmonary artery.

this report and their clinical features are given in table 2 .

The mean age was 16 (SD 9.6) years (range 3-49 years) and 82 patients were under 20 (fig 1). All patients had rheumatic valvular disease and 33 were operated on during the acute phase of the disease. In 13 patients the operation was performed on an emergency basis. Associated tricuspid valve regurgitation required annuloplasty in 11 cases, while concomitant aortic valve disease necessitated aortic valve replacement in 23 patients.

Intraoperative pressures were measured both before and after mitral valve annuloplasty in most patients (table 3 ), except when bypass had to be instituted rapidly because of a low cardiac output. Before bypass the mean left atrial $\mathrm{V}$ wave was 47.6 (SD 21.0) $\mathrm{mm} \mathrm{Hg}$ (range 13-100 $\mathrm{mm} \mathrm{Hg}$ ). The mean systolic pulmonary artery pressure of the group was $49.3 \quad(13.8) \quad \mathrm{mmHg}$ (range $20-80$ $\mathrm{mm} \mathrm{Hg}$ ). After bypass there was a striking decline in left atrium pressures, but the pulmonary artery pres-

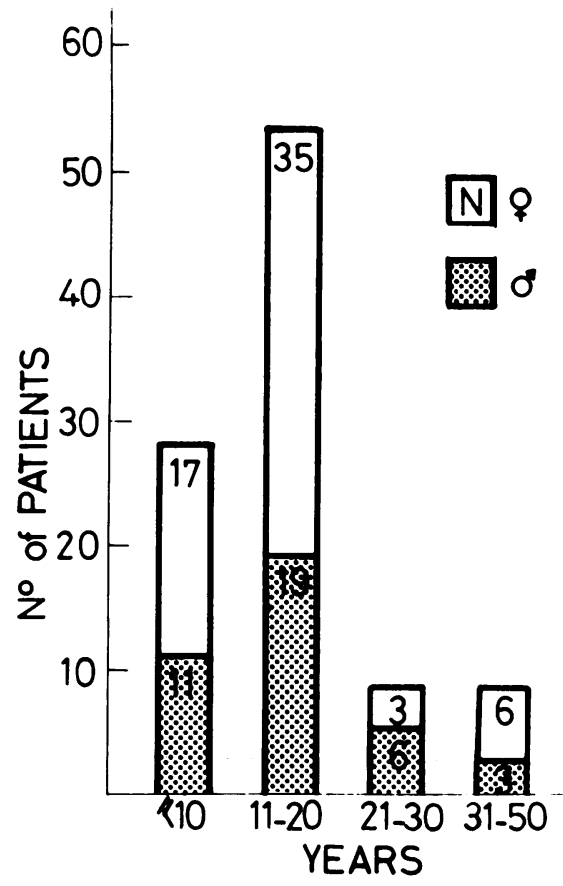

Fig 1 Age and sex of patients at operation.

sure dropped less. The mean gradient across the mitral valve after repair was $3.7(2.7) \mathrm{mm} \mathrm{Hg}$ (range 0-10 $\mathrm{mm} \mathrm{Hg}$ ).

At operation the mitral valve annulus was found to be dilated in all patients, in 57 cases considerably so. The chordae tendineae were elongated in 69 patients and ruptured in six. The left atrium was dilated in 85 patients, considerably so in 36 .

Standard cardiopulmonary bypass with moderate systemic hypothermia $\left(25-30^{\circ} \mathrm{C}\right)$ was used in all patients. Early in the series one or more periods of ischaemic arrest (15 minutes aortic cross clamp followed by three minutes of coronary perfusion) were used. More recently myocardial protection was achieved with cold, asanguinous potassium cardioplegic solution (potassium $30 \mathrm{mmol}(\mathrm{mEq}) / \mathrm{l})$. The method of mitral valve annuloplasty varied: the Reed measured asymmetric annuloplasty ${ }^{19}$ was used almost exclusively in our first 37 patients, while a posterior plication annuloplasty (modified from that of Burr et $a l^{20}$ ) was preferred subsequently (56 patients). A Carpentier ring ${ }^{21}$ was used in seven patients.

After mitral valve annuloplasty the valve was tested by injection of fluid under pressure (manually or from the cardioplegic line) into the left ventricle. Localised regurgitant jets were frequently corrected with a single additional plication suture. After bypass simultaneous measurement of left atrium and 

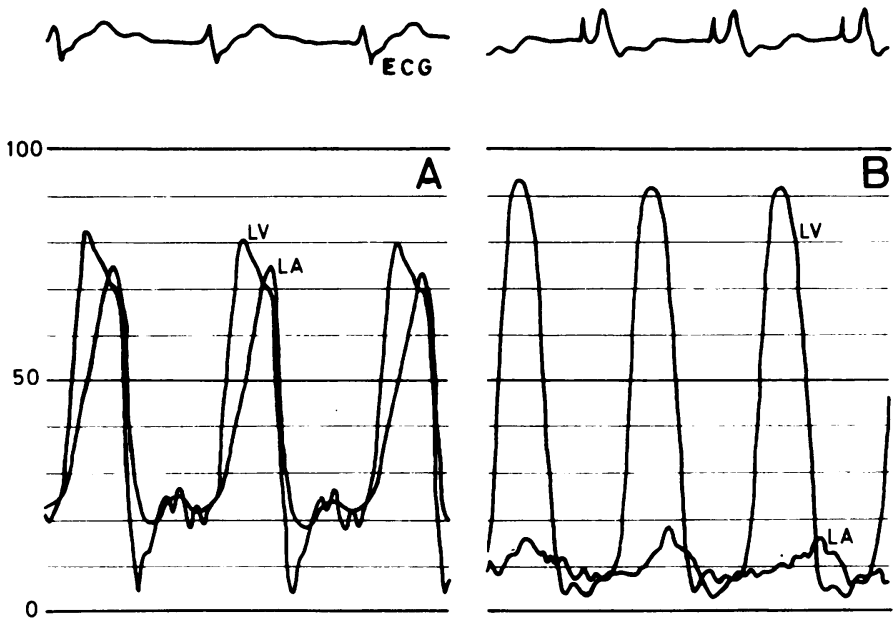

Fig 2 Simultaneous left atrial ( $L A)$ and left ventricular $(L V)$ intracavitary pressures. (A) Before mitral valve annuloplasty, with a large $V$ wave indicating severe mitral regurgitation. $(B)$ After mitral valve annuloplasty, showing a competent, non-stenotic mitral valve. $E C G$-electrocardiogram. left ventricular intracavitary pressures provided an objective assessment of the functional state of the mitral valve (fig 2 ).

In our experience patients from this population underestimate their symptoms and so in assessing results we combined symptoms and clinical findings and grouped the patients into four categories: excellent-patients with no symptoms (New York Heart Association (NYHA) class I) and a competent and non-stenotic mitral valve; good-patients in class I but mild residual mitral valve dysfunction; satisfactory - patients in class I or II and moderate mitral valve dysfunction; poor-patients in class III with or without signs of severe mitral valve dysfunction.

Valve failure rate was defined as regurgitation requiring reoperation or resulting in death. To identify factors predisposing to valve failure results were analysed according to age (under 15 years and 15 years or over), emergency versus elective operation, NYHA functional class, the presence or absence of acute rheumatic carditis at the time of surgery, and the various techniques of mitral valve annuloplasty used.

Actuarial survival rates were calculated and the curves constructed according to the method of Grunkemeier and Starr. ${ }^{22}$ Statistical significance was determined by the $\chi^{2}$ method with the aid of $2 \times 2$ contingency tables and Yates's correction for small numbers.

\section{Results}

\section{MORTALITY}

The operative mortality rate (defined as failure to leave hospital alive) was $6 \%$. There were no intra- operative deaths and all deaths occurred from three to 33 days after surgery. The causes of death are shown in table 4 . Death was not related to the valve in four patients. The other two patients, who had acute rheumatic carditis at the time of annuloplasty, had sudden early disruption of the repair. Both died after emergency reoperation. There were 14 known late deaths $-4.1 \%$ per patient year (table 4 ). At least seven patients died because of chronic mitral regurgitation, three during or after reoperation. One patient died a year after operation from left ventricular dysfunction and one late death was due to trauma. In five patients the cause of death was unconfirmed but presumed to be cardiac.

\section{REOPERATION}

Apart from the two patients with sudden disruption in the early postoperative period, 25 patients had a reoperation ( $7.4 \%$ per patient year) 3-72 months after the initial procedure (mean 25 months). All patients had recurrent or residual mitral regurgitation, due to progression of rheumatic carditis or disruption of the repair or both (seven patients). Mitral valve replacement was performed in all cases.

Table 4 Causes of death

\begin{tabular}{lr}
\hline Cause & No \\
\hline Early deaths & \\
Disruption of repair & 2 \\
Respiratory failure & 2 \\
Haemorrhage & 1 \\
Arrhythmia & 1 \\
Late deaths & \\
Valve related (residual mitral regurgitation) & 7 \\
Left ventricular dysfunction & 1 \\
Trauma & 1 \\
Unknown & 5 \\
\hline
\end{tabular}


Table 5 Clinical condition of 43 survivors without reoperation

\begin{tabular}{|c|c|}
\hline Result & No (\%) \\
\hline $\begin{array}{l}\text { Excellent } \\
\text { Good } \\
\text { Satisfactory } \\
\text { Poor }\end{array}$ & $\begin{array}{rr}9 & (20.9) \\
18 & 41.8 \\
11 & (25.6) \\
5 & (11.7)\end{array}$ \\
\hline Total & $43(100 \cdot 0)$ \\
\hline
\end{tabular}

\section{MORBIDITY}

There were two cases of systemic embolism, neither of which had permanent sequelae $(0.65 \%$ per patient year). In five patients a moderate to severe degree of haemolysis developed after repair. In three of these the haemolysis subsided within three months, after one to three transfusions of blood. In the remainder it necessitated reoperation and partial disruption of the repair was found.

\section{CLINICAL CONDITION OF SURVIVORS}

Because of the logistical problems of follow up in an underdeveloped population 13 patients were lost. The total duration of follow up for the remaining patients was 339.9 patient years (patients were followed from operation to the time of analysis or to reoperation or death). The average duration of follow up for survivors was 4.8 (SD 1.2) years, range 3-9 years. The overall actuarial survival for those who survived operation was $82 \%$ at five years and $76 \%$ at eight years (fig 3). Survival without reoperation (that is, with the original repair) at five and eight years was $56 \%$ and $42 \%$.

Forty three survivors who had not been lost to follow up and who had not had reoperation were available for clinical assessment. Their condition was categorised as excellent in nine, good in 18,

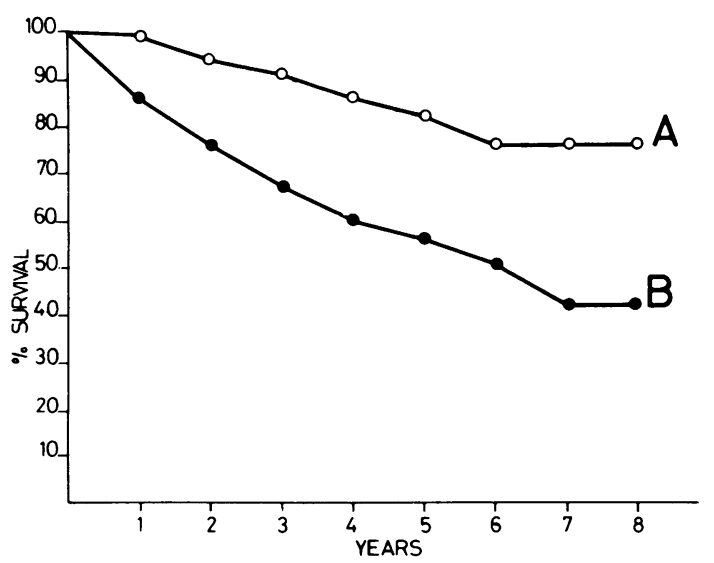

Fig 3 Actuarial survival after mitral valve annuloplasty: (A) overall survival (operative survivors); (B) survival without reoperation (that is, with original repair).
Table 6 Valve failure rate for different subgroups

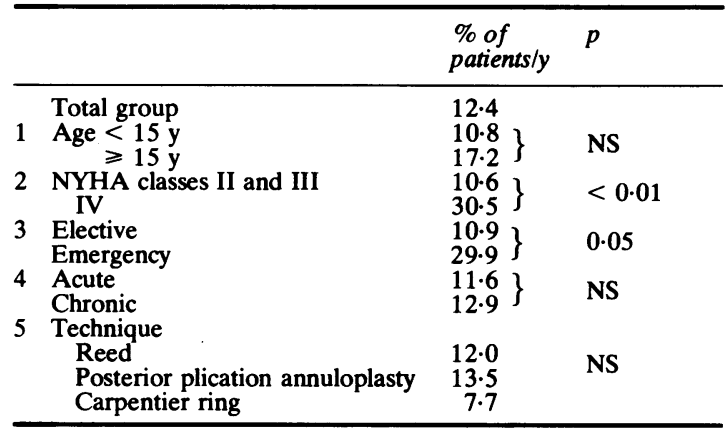

NYHA-New York Heart Association; NS—not significant.

satisfactory in 11 , and poor in five (table 5). The last category includes three patients in class III with severe mitral valve dysfunction and two who deny symptoms (class II) but who have clinically severe mitral regurgitation and will require reoperation.

In summary, 27 of the 94 operative survivors had a successful mitral valve annuloplasty (excellent or good late results), while in 44 patients the repair failed (poor result, reoperation, or death). This figure includes the 11 patients with a "satisfactory" result who will undoubtedly deteriorate further, as all have at least moderate mitral regurgitation.

FACTORS AFFECTING VALVE FAILURE RATE The valve failure rate was $12.4 \%$ per patient year (table 6). To identify possible predisposing factors the incidence was calculated for different subgroups: patients under 15 years had a lower failure rate than those of 15 years and over, but the difference was not significant. Patients who had been in classes II and III did significantly better $(p<0.01)$ than those in class IV, and the patients who had been operated on electively did better than those who had had emergency procedures $(p=0.05)$. There was no significant difference between the patients operated on during the acute phase and those with chronic rheumatic carditis. No difference was found between the results of the Reed and posterior plication techniques; the number of patients with a Carpentier ring was too small for statistical evaluation.

\section{Discussion}

Substitute heart valves have major limitations in a third world population. ${ }^{23}$ Mechanical valves have a high incidence of thromboembolic complications because good anticoagulation is the exception rather than the rule. Bioprosthetic valves, while still an acceptable alternative in women of childbearing age, have a high failure rate, especially in the young.

By comparison with the hazards and limitations of 


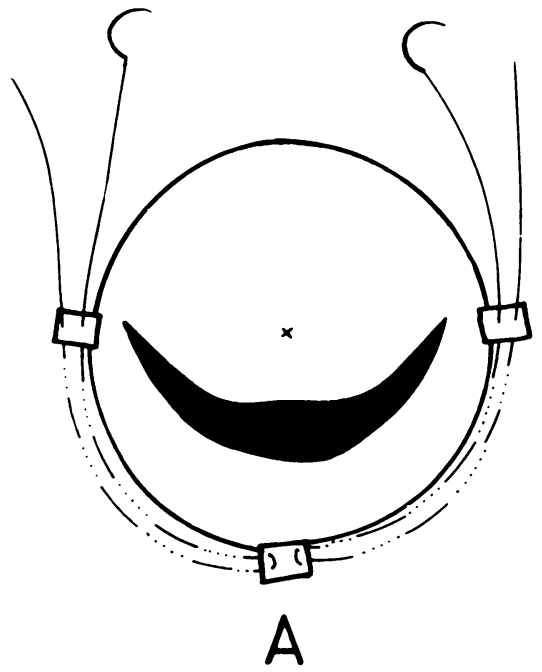

mechanical valves and bioprostheses in the same population group, mitral valve annuloplasty remains an attractive procedure for selected patients. Reparative techniques, however, are not as reproducible and the results not as predictable as is valve replacement. ${ }^{18}$ Our review of several recent reports of conservative procedures ${ }^{182-26}$ clearly showed that the indications and results are not uniform. All our patients had rheumatic carditis and rheumatic valvulitis is associated with the worst long term results. The disease is progressive, especially in young patients in the second and third decades of life. On the other hand, our patients have shown poor compliance when prescribed prophylactic penicillin.

Stirred by the inadequacies of mitral valve replacement we have followed a policy of mitral valve conservation whenever possible. More than one third of the patients subjected to mitral valve surgery during the period of this study had conservative procedures. This proportion is lower than those of Reed et $a l^{24}$ and Shore $e t a l,{ }^{26}$ but is similar to that of Duran et al. ${ }^{25}$ At five years the actuarial survival of our patients after mitral valve annuloplasty was similar to that after mitral valve replacement (73\%) in the same population group (unpublished data).

The average age of patients in this series (16 years) is much lower than that of most other published series of patients having conservative mitral valve procedures, ${ }^{202728}$ even for predominantly rheumatic groups. ${ }^{29}$ Our concern about the fate of substitute valves in children increased our awareness of the need to preserve the native mitral valve. Indeed, in patients subjected to mitral valve annuloplasty better results were noted in the younger than

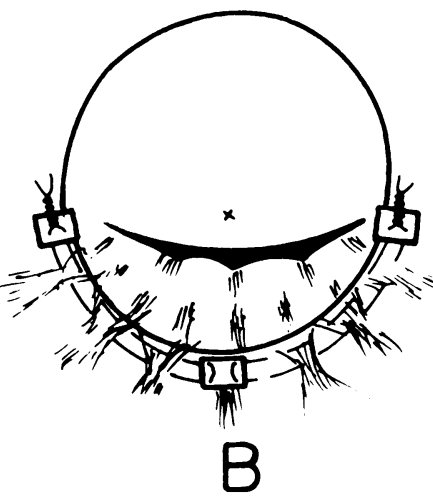

Fig 4 Technique of posterior plication annuloplasty (modified from Burr et $\left.a l^{20}\right)$.

in the older age group, although the difference did not reach significance. Much to our surprise, no difference was found between patients with acute and chronic rheumatic carditis. The oedema of the tissues that characterises the former did not seem to influence the ultimate result. Presumably rheumatic activity declines in the early postoperative period. Provided that the process is not reactivated the repair can be durable.

There was a significant difference between the results of emergency and of elective operations and between the results in functional classes II and III and in class IV. This is hardly surprising since most of the patients in the emergency and class IV groups were desperately ill, often with very poor myocardial function. In these cases the best possibility of survival rests on perfect haemodynamics and absolute competence of the mitral valve. In these patients therefore we now invariably replace the valve.

Initially the technique preferred was Reed's measured asymmetrical annuloplasty. ${ }^{19}$ While the initial functional result was satisfactory the poor late results were soon apparent. We considered that failure occurred because the posterior annulus was partially unprotected, with continued rheumatic activity causing further dilatation. Consequently that technique was abandoned in favour of a posterior plication of the annulus, modified from the technique described by Burr et al. ${ }^{20}$ Our modification of this operation consisted of placing two half sutures through a single median posterior teflon pledget (fig 4 ), thus completely protecting the posterior annulus from further dilatation. Surprisingly on analysing these results we found no difference between the 
two groups. Recent reports ${ }^{24-26}$ confirm identical results with different techniques. In this series the experience with the Carpentier ring was limited to seven cases and these patients have done well. Implantation of the ring was attempted in another four cases. Because of appreciable residual regurgitation the mitral valve had to be replaced at the same operation. The technique appeared to have good late results but a high intraoperative failure rate. We have since realised that Carpentier ring insertion is only part of a more complete valvuloplasty..$^{30}$ The ring also has the advantage of correcting annular deformity. It does not, however, correct abnormalities in other components of the mitral valve apparatus. When these predominate implantation of the ring alone fails to produce a.durable repair.

In this series there was a low incidence of thromboembolism. An embolic rate of less than one episode per 100 patient years compares favourably with the rates of other authors 2526 and is only slightly higher than the $0.4 \%$ reported by Reed et al..$^{24}$ To the best of our knowledge, haemolysis related to mitral valve annuloplasty has not been previously reported. In our series, it was an important cause of morbidity (five cases). In three patients haemolysis subsided in three months at most, but required repeated blood transfusions. In the other two cases haemolysis required reoperation. In both these cases partial disruption of the repair was found.

The long term clinical condition of survivors remains uncertain. At five years only $35 \%$ of our patients had normal or near normal mitral valve function. At eight years the figure had dropped to $27 \%$. It has long been claimed that residual regurgitation is progressive and of poor prognostic significance ("regurgitation begets regurgitation"31). This is especially true when there is reactivation or continued rheumatic activity. In the past three years 20 of the 28 patients initially classified as "satisfactory" have either died or had reoperation. We presume that the remainder will follow suit.

Why should mitral valve annuloplasty have such a high failure rate in underdeveloped populations? Certainly failure to take prophylactic penicillin must contribute, but it cannot be the only factor.

Carpentier ${ }^{32}$ has emphasised that rheumatic carditis invariably affects all the components of the mitral valve apparatus-namely, the annulus, leaflets, papillary muscles, and chordae tendineae. Correction of only one abnormal component-for example, the annulus-results in an incomplete repair $^{2130}$ and therefore is doomed to failure. Moreover, the annulus is not only dilated but also frequently deformed. Conventional suture annuloplasties do not correct this abnormality.
Our awareness of these facts increased pari passu with our disappointment in the results of mitral valve annuloplasty. Consequently, we have adopted Carpentier's approach of a complete valvuloplasty and abandoned conventional annuloplasty techniques. The early results of mitral valvuloplasty are encouraging and are the subject of another report. ${ }^{33}$

We thank Mrs Marsha Krengel for her assistance with the typing and revision of the manuscript.

\section{References}

${ }^{1}$ Davilla JC, Magilligan DJ, Lewis JW jun. Is the Hancock porcine valve the best cardiac valve substitute today? Ann Thorac Surg 1978;26:303-16.

${ }^{2}$ Fowler NO, Van Der Bel-Kahn JM. Operation on the mitral valve: a time for weighing the issues. $A m$ J Cardiol 1980;46:159-62.

${ }^{3}$ Carpentier A, Dubost C, Lane E, et al. Continuing improvement in valvular bioprostheses. $J$ Thorac Cardiovasc Surg 1982;83:27-42.

${ }^{4}$ Bjork VO, Henze A. Ten years' experience with the Björk-Shiley tilting disc valve. $J$ Thorac Cardiovasc Surg 1979;78:331-42.

${ }^{5}$ Emery RE, Nicoloff DM. St Jude medical cardiac valve prosthesis. In vitro studies. J Thorac Cardiovasc Surg 1979;78:269-76.

' Bonchek LI. Current status of cardiac valve replacement. Selection of a prosthesis and indications for operation. Am Heart J 1981;101:96-106.

${ }^{7}$ Moggio RA, Hammond GL, Stansel HC jun, Glenn WWL. Incidence of emboli with cloth-covered Starr-Edwards valve without anticoagulation and varying forms of anticoagulation. Analysis of 183 patients followed for $2 \frac{1 / 2}{2}$ years. J Thorac Cardiovasc Surg 1978;75:296-9.

${ }^{8}$ Copans H, Lakier JB, Kinsley RH, Colsen PR, Fritz VU, Barlow JB. Thrombosed Björk-Shiley mitral prostheses. Circulation 1980;61:169-74.

${ }^{9}$ Kinsley RH, Colsen PR, Antunes MJ. Hall-Kaster valve replacement in a third world population group. Thorac Cardiovasc Surg (in press).

${ }^{10}$ Spray TL, Roberts WC. Structural changes in porcine xenografts used as substitute cardiac valves. Gross and histologic observation in 51 gluteraldehyde-preserved Hancock valves in 41 patients. Am J Cardiol 1977;40:319-30.

1 Geha AS, Laks H, Stansel HC jun, et al. Late failure of porcine valve heterografts in children. $J$ Thorac Cardiovasc Surg 1979;78:351-64.

12 Silver MM, Pollock J, Silver MD, Williams WG, Trusler GA. Calcification in porcine xenografts in children. Am J Cardiol 1980;45:685-9.

${ }^{13}$ Morris DC, King SB III, Douglas JS jun, Wichliffe EW, Jones EL. Hemodynamic results of aortic valvular replacement with the porcine xenograft valve. Circulation 1977;56:841-4.

${ }^{14}$ McLaren M, Hawkins DM, Koornhof HJ, et al. Epidemiology of rheumatic heart disease in black schoolchildren in Soweto, Johannesburg. Br Med J 1975;iii:474-8.

15 Louw JWK, Kinsley RH, Dion RAE, Colsen PR, Gird- 
wood RW. Emergency heart valve replacement. An analysis of 170 patients. Ann Thorac Surg 1980;29:415-22.

${ }^{16}$ Dubost C. Evaluation of surgery for mitral valve disease. Am Heart J 1971;82:143-8.

${ }^{17}$ Bonchek LI. Correction of mitral valve disease without valve replacement. Am Heart J 1982;104:865-8.

${ }^{18}$ Carpentier A, Chauvaud S, Fabiani JN, et al. Reconstructive surgery of mitral valve incompetence. Ten year appraisal. J Thorac Cardiovasc Surg 1980;79:338-48.

${ }^{19}$ Reed GE, Tice DA, Clauss RH. Asymmetric exaggerated mitral annuloplasty. Repair of mitral insufficiency with hemodynamic predictability. $J$ Thorac Cardiovasc Surg 1965;49:752-61.

${ }^{20}$ Burr HB, Krayenbuhl C, Sutton M St J, Paneth M. The mitral plication suture. J Thorac Cardiovasc Surg 1977;73:589-95.

${ }^{21}$ Carpentier A, Deloche A, Dauptain J, et al. A new reconstructive operation for correction of mitral and tricuspid insufficiency. J Thorac Cardiovasc Surg 1971;61:1-13.

${ }^{22}$ Grunkemeier G, Starr A. Actuarial analysis of surgical results: rationale and method. Ann Thorac Surg 1977;24:404-8.

${ }^{23}$ Kinsley RH. Valve replacement. Ann Life Ins Med 1980;6:185-201.

${ }^{24}$ Reed GE, Pooley RW, Moggio RA. Durability of measured mitral annuloplasty. Seventeen year study. $J$ Thorac Cardiovasc Surg 1980;79:321-5.
${ }^{25}$ Duran CG, Pomar JL, Revuelta JM, et al. Conservative operation for mitral insufficiency. Critical analysis supported by post-operative hemodynamic studies of 72 patients. J Thorac Cardiovasc Surg 1980;79:32637.

${ }^{26}$ Shore DF, Wong P, Paneth M. Results of mitral valvuloplasty with a suture plication technique.J Thorac Cardiovasc Surg 1980;79:349-54.

${ }^{27}$ Duran CG, Ubago JLM. Clinical and hemodynamic performance of a totally flexible prosthetic ring for atrioventricular valve reconstruction. Ann Thorac Surg 1976;22:458-63.

${ }^{28}$ Carpentier A, Relland J, Deloche A, et al. Conservative management of the prolapsed mitral valve. Ann Thorac Surg 1978;26:294-302.

${ }^{29}$ Lessana A, Herreman F, Boffety C. Hemodynamic and cineangiographic study before and after mitral valvuloplasty (Carpentier's technique). Circulation 1981;64:195-202.

${ }^{30}$ Carpentier A. Mitral valve reconstructive surgery. In: Robb C, Smith R, eds. Operative surgery. London: Butterworth, 1977:169-77.

${ }^{31}$ Edwards JE, Burchell HG. Endocardial and mitra! lesions (jet impact) as possible sites of origin of murmurs. Circulation 1958;18:946-60.

${ }^{32}$ Carpentier A. Plastic and reconstructive mitral valve surgery. In: Kalmanson $\mathrm{D}$, ed. The mitral valve. Acton, Mass: Publishing Sciences Group, 1976: $527-40$.

${ }^{33}$ Antunes MJ, Colsen PR, Kinsley RH. Mitral valvuloplasty. A learning curve. Circulation (in press). 